\title{
A efêmera e fatal Mina de Cata Branca: mineração e trabalho numa companhia aurífera inglesa em Minas Gerais (1832-1844)
}

\author{
Rafael de Freitas e Souza*
}

Resumo: O artigo analisa a história da companhia aurífera britânica, Brazilian Company, que atuou em Itabira do Campo, Minas Gerais, entre 1832 e 1844. Apoiados por censos demográficos e informações coligidas nas obras dos viajantes europeus que a visitaram ou sobre ela escreveram tentaremos demonstrar que as falhas administrativas e as adversas condições de trabalho a que estavam submetidos os trabalhadores livres e escravos, nacionais e estrangeiros, estão diretamente relacionadas à falência precoce da empresa.

Palavras-chave: Minas Gerais; mineração; trabalho.

\begin{abstract}
The article analyzes the history of British gold mining company, Brazilian Company, who starred in Itabira do Campo, Minas Gerais, between 1832 and 1844 . Supported by demographic censuses and information gathered in the works of European travelers who visited or wrote about it try to demonstrate that administrative shortcomings and the adverse working conditions to which the free and slave, national and foreign workers were subjected are directly related to early failure of the company.
\end{abstract}

Keywords: Minas Gerais; mining; work.

\section{Introdução}

O processo de abertura do mercado brasileiro iniciado dois anos após a transferência da Corte Portuguesa para o Brasil com o franqueamento dos portos às nações amigas em 1810 foi consumado no Primeiro Reinado através da publicação do Decreto de 16 de setembro de 1824 que tinha o propósito de atrair e fixar "estrangeiros hábeis, e capitalistas que possam fundar estabelecimentos grandes",

* Doutor em História Social (USP). Professor do Instituto Federal de Educação do Sudeste de Minas Gerais - Campus Rio Pomba. E-mail: rf.souza@bol.com.br. 
inclusive destinadas à extração de ouro. ${ }^{1}$ Em outras palavras, depois dos portos, abriram-se as bocas das minas à iniciativa estrangeira. Graças a esta concessão, ao longo do século XIX antigas minas consideradas improdutivas ou desativadas foram adquiridas por companhias estrangeiras, sobretudo inglesas. Abria-se, então, nova fase na história da mineração e da história social do trabalho em Minas Gerais, o denominado "período inglês". 2

A presença inglesa em Minas Gerais no século XIX é um dos capítulos mais marcantes da nossa história. Podemos falar num segundo rush do ouro, embora este possua razões e consequências distintas às do primeiro ocorrido no século XVIII quando os primeiros garimpeiros desbravaram a região e se depararam com toneladas do ouro secundário disponível nos ribeiros, embora também explorassem as jazidas primárias com técnicas e instrumentos típicos daquela fase (como a bateia, o carumbé e a alavanca).

Suprassumindo os vieses tecnicista e economicista tentaremos demonstrar que a sede do lucro rápido e a negligência com a segurança no local de trabaIho foram os principais fatores que provocaram tanto a falência precoce do empreendimento quanto a morte dos mineiros da mina de Cata Branca onde a vida era menos preciosa que o ouro.

Assim como diversas localidades de Minas Gerais, a freguesia de Nossa Senhora da Boa Viagem da Itabira do Campo, 3 pertencente ao Termo de Vila Rica, nasceu sob a faina da busca pelo ouro nos ribeiros e faldas das montanhas no século XVIII. Nesta paragem encontrava-se a mina de Cata Branca. ${ }^{4}$ Desconhecemos o

1 BRASIL. Collecção das leis do Brazil, desde a independência: 1822-1825. Ouro Preto: Typografia de Silva, 1829, p. $426 \mathrm{~s}$.

2 A história destes novos empreendimentos vem sendo analisada sob diferentes pontos de vista pela historiografia. Robert Slenes e os irmãos Martins debateram amplamente a respeito de seus impactos na economia mineira oitocentista. Douglas Cole Libby analisou o largo uso que os ingleses fizeram da mão de obra escrava para mover suas engrenagens. Marshall C. Eakin demonstrou como uma pequena comunidade agrária foi transformada numa cidade industrial após a chegada dos ingleses para operar a mina de Morro Velho nos séculos XIX e XX, atento às inovações tecnológicas e seus resultados econômicos e sociais destacando ainda o poder político da empresa. Yonne de Souza Grossi investigou a organização e as lutas dos operários na mesma mina no século XX. Tânia Maria F. Souza investigou as mudanças tecnológicas introduzidas pelos ingleses na mineração no século das máquinas. Fábio Carlos da Silva pesquisou a história a legislação brasileira que regulamentou estes empreendimentos e as relações que figuras notáveis do império estabeleceram com a National Brazilian Minining Association. Vale destacar a original perspectiva adotada por Fabiano Lopes de Paula que desenvolveu estudo arqueológico do espaço da morte nas minerações inglesas revelando os diferentes significados do cemitério anglicano da mina de Morro Velho. Cf. SLENES, Robert W. "Os múltiplos de porcos e diamantes: a economia escravista de Minas Gerais no século XIX”. Cadernos IFCH. Campinas: UNICAMP, 1985. LIBBY, Douglas Cole. Transformação e trabalho em uma economia escravista: Minas Gerais no século XIX. São Paulo: Brasiliense, 1988. EAKIN, Marshall C. British enterprise in Brazil: The St. John d'el Rey Mining Company and the Morro Velho Gold Mine, 1830-1960. Duke University Press: Durham and London, 1989. SOUZA, Tânia Maria Ferreira de. "Onde o sol nunca brilha: uma história dos investimentos britânicos e da mudança tecnológica na mineração aurífera de Minas Gerais no século XIX". 2002. (Tese de Doutorado em História, FFLCH, Universidade de São Paulo, São Paulo, 2002). SILVA, Fábio Carlos da. "Barões do ouro e aventureiros britânicos no Brasil: a companhia inglesa de Macaúbas e Cocais (1828-1912)”. 1997. (Tese de Doutorado em História Econômica, FFLCH, Universidade de São Paulo, São Paulo, 1997). PAULA, Fabiano Lopes de. "O espaço da morte nas minerações inglesas em Minas Gerais - o exemplo de Morro Velho”. 1997. (Dissertação de Mestrado em Arqueologia, FFLCH, Universidade de São Paulo, São Paulo, 1997).

3 Segundo Barbosa, "a freguesia foi criada por Alvará de 3 de abril de 1745 e tornada colativa por Alvará de 16 de janeiro de 1752. O distrito de Itabira do Campo foi elevado a município desmembrado de Ouro Preto, pela Lei $n^{\circ} 843$, de 7 de setembro de 1823, com a denominação de Itabirito." BARBOSA, Waldemar de Almeida. Dicionário histórico-geográfico de Minas Gerais. Belo Horizonte: Ed. Saterb, 1971, p. 224.

4 De acordo com o relatório do engenheiro de minas, Eugène d'Osery "a mina de Cata Branca parece ter sido explorada antigamente pelos portugueses, sob o nome de Buraco da Mônica". Sem precisar claramente o ano, o autor cita a ocorrência do desabamento de uma parte das obras que "acarretou a morte de várias pessoas, fazendo com que sua exploração fosse suspensa" - Apud CASTELNAU, Francis. Expedições às regiões centrais da América do Sul. Tradução Olivério M. de Oliveira Pinto. Tomo I. São Paulo: 
nome de seu primeiro proprietário. Paul Ferrand informa que o conde de Linhares 5 a adquiriu em 1830 por 22.000 cruzados (aproximadamente 22.000 francos). Em 28 de janeiro de 1832, Linhares vendeu-a ao Sr. Aristides Franklim Mornay por 78 contos de réis (cerca de 195.000 francos) representante da Brazilian Company Limited (fundada com capital nominal de 60.000 libras). O viajante britânico, Richard Burton, traça outra história das transações de compra e venda da mina de Cata Branca. Segundo ele,

As terras, pertencentes originalmente a colonos pobres, brasileiros e portugueses, passaram para as mãos do Conde de Linhares que vendeu a concessão ao falecido anglo-americano, Dr. Clife. Este, homem de energia verdadeiramente transatlântica, e de muita confiança em si mesmo, partiu com seu direito à 'Brazilian Company, fundou-a em 28 de janeiro de 1833 e, naquele ano, o superintendente, Mr. A. F. Mornay, completou a compra. ${ }^{6}$

O período de atividade extrato-produtiva da mina de Cata Branca foi curto devido a um grave acidente que ceifou a vida de dezenas de trabalhadores em 1844, além de outros ocorridos anteriormente. Por isso, de acordo com Douglas Libby (1988), sua história "é uma das mais curtas e trágicas dentre as experiências dos empreendimentos estrangeiros em Minas". ${ }^{7}$ O valor de suas ações decaiu 70\% em Londres por não ter proporcionado nenhum dividendo aos acionistas.

A participação da Brazilian Company na produção aurífera da Província de Minas Gerais entre 1820 e 1860 foi de: produção em libras-peso = 3.167; percentual da produção contabilizada das companhias inglesas $=3,5 \%$ e percentual da produção global $=1,8 \% .{ }^{8}$ Números insignificantes se comparados aos índices da Imperial Brazilian Mining Association e da Saint John d'El Rey Mining Company que contabilizaram, respectivamente, $20,6 \%$ e $30,1 \%$ da produção global no mesmo período. Segundo Roberto Borges Martins, a Brazilian Company produziu “1.181,3 quilos de ouro entre 1840 e 1844 , com um rendimento de 12,8 gramas de ouro por tonelada de minério". 9 No ano seguinte, foi vendida a outra companhia britânica, a Saint John d'El Rey Mining Company. ${ }^{10}$

Companhia Editora Nacional, 1949, p. 163 s.

5 D. Vitório Maria de Souza Coutinho, o segundo Conde de Linhares. Seu pai, D. Rodrigo de Sousa Coutinho, o primeiro Conde de Linhares, faleceu em 1812.

6 BURTON, Richard Francis. Viagem do Rio de Janeiro a Morro Velho. Tradução David J. Junior; apresentação e notas Mário Guimarães Ferri. Belo Horizonte: Ed. Itatiaia; São Paulo: Edusp, 1976, p. 163. Observe que no Mappa nominal dos habitantes da Parochia de N. Snr. ${ }^{a}$ da B. Viagem da Itabira do Campo datado de 1831 abaixo citado consta o nome de José Estevão Cliff, branco, 26 anos, solteiro, natural dos Estados Unidos, médico e empregado na mineração. De acordo com Leandro Braga de Andrade, esta segunda transação “foi registrada no primeiro tabelião de Ouro Preto, tendo sido paga à vista, em moedas e cobre". In: ANDRADE, Leandro Braga. "Fortunas subterrâneas: Negociantes da capital da província de Minas Gerais e as companhias inglesas de mineração". In: XV Seminário sobre a economia mineira - 30 anos, 2012, Diamantina - MG. Anais... Diamantina, 2012, p. 8.

7 LIBBY. Transformação e trabalho em uma economia escravista, p. 275.

8 LIBBY. Transformação e trabalho em uma economia escravista, p. 270.

9 MARTINS, Roberto Borges. A história da mineração no Brasil. Trad. Isabel Murat Burbridge e Suzan L. Koslowski. São Paulo: Empresa das Artes. 1989. Edição bilíngue, p. 49.

10 FERRAND, Paul. O ouro em Minas Gerais. Tradução Júlio Castagnõn Guimarães. Notas de João Henrique Grossi, Friedrich E. Renger, estudos críticos João Henrique Grossi et al. Belo Horizonte: Sistema Estadual de Planejamento; Centro de Estudos Históricos e Culturais. Fundação João Pinheiro, 1998, p. 185. LIBBY, Douglas Cole. Transformação e trabalho em uma economia escravista: Minas Gerais no século XIX. São Paulo: Ed. Brasiliense, 1988, p. 186 e 275 s. 


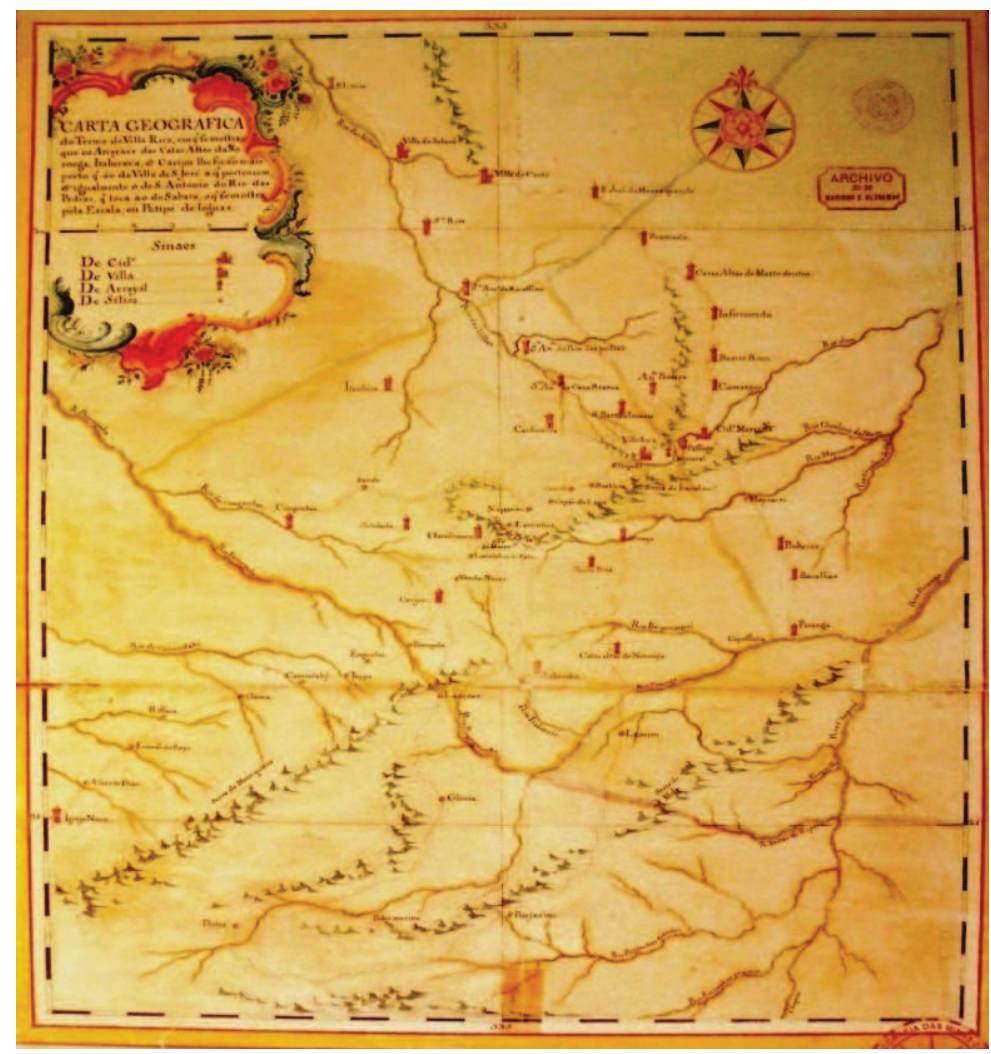

Legenda: Carta Geográfica do Termo de Villa Rica. Ca. 1766. Observe Itabira no detalhe. Fonte: COSTA, Antônio Gilberto et al. Cartografia das Minas Gerais da Capitania à Província. 2002. Disponível em: www.arq.ufmg.br/nehcit/itabirito/mapas/mapas.php?mapa $=2 \&$ titulo=Carta\%2ogeogr\%C3\%A1fica\%20 do\%20termo\%20de\%20Vila\%20Rica. Acesso em 21/09/2015.

\section{Demografia e trabalho em Itabira do Campo}

Aproximadamente três meses antes da aquisição da mina pelos ingleses o juiz de paz da paróquia de Itabira do Campo, o major Joaquim José de Oliveira Mafra, apresentou ao presidente da província de Minas Gerais, no dia 8 de novembro de 1831, o "Mappa nominal dos habitantes da Parochia de N. Snr. ${ }^{a}$ da B. Viagem da Itabira do Campo" fruto do recenseamento realizado naquele ano acrescido do arrolamento das "pessoas que têm fábricas no mesmo." 11

O recenseamento de 1831 é um documento valioso não apenas para a história demográfica. Através dele podem-se obter dados relativos à história da escravidão, do trabalho, da família e da educação das localidades mineiras do segundo quartil do século XIX. Ele atesta e enumera a quantidade, a qualidade, a condição, a idade, o estado civil e a ocupação de todos os moradores da Paróquia de Nossa Senhora da Boa Viagem da Itabira do Campo antes do "período inglês".

Em 1831 a população de Itabira do Campo estava distribuída em 218 fogos (incluindo a lavra) e composta por 840 homens e mulheres livres, 303 escravos e 12 forros, totalizando 1.155 pessoas. A maioria dos proprietários de escravos possuía entre um e dez cativos. Apenas cinco dentre eles ultrapassavam a dezena. Esta era, aliás, a média da estrutura de posse de escravos em Minas Gerais no mesmo período. O maior proprietário era o lavrador Francisco Rodrigues de Carvalho com 26 cativos. Acima dele, somente o dono da lavra.

11 Arquivo Público Mineiro. Mapas de População (1831). MP-CX 01-DOC.04. Disponível em: http://www.siaapm.cultura.mg.gov.br/modules/mapas_populacao/brtacervo.php?cid=64. Acesso em 12/07/2014. 
Dentre os 218 fogos, excetuando-se a lavra, apenas 56 contavam com o braço escravo. Não obstante, numa sociedade escravocrata, o escravismo era o principal substrato, pois tornar-se senhor de escravo ou afastar-se do cativeiro balizava as relações de trabalho, sociais e era elemento definidor do ser e do poder.

A população economicamente ativa dos livres e escravos de Itabira do Campo em 1831 estava distribuída em, aproximadamente, 35 ocupações/ofícios além dos 35 estudantes. A maior parte estava empregada no setor de fiação de algodão e tecidos (fiandeiras, costureiras e tecedeiras) e na mineração (mineiros e faiscadores), seguido pelas atividades agrícolas (roceiro e lavrador). À margem da sociedade gravitavam seus mendigos, aleijados e outros sem as ocupações definidas no documento.

No que tange à lavra de Cata Branca em novembro de 1831 o recenseamento mostra que seu quadro funcional era composto por 75 indivíduos: 1 norte-americano, 2 ingleses, 3 pardos livres e 69 cativos (34 homens e 35 mulheres). Este equilíbrio entre os sexos é surpreendente, pois o padrão da divisão sexual do trabalho na mineração de maneira geral era o predomínio da força de trabalho masculina. Quanto aos escravos, a maioria absoluta foi classificada como Angola. Apesar da pouca legibilidade do documento faz-se imprescindível sua transcrição abaixo para a posterior análise de seus dados:

Tabela 1 - Força de trabalho escrava e livre da Mina de Cata Branca (1831)

\begin{tabular}{|c|c|c|c|c|c|}
\hline Habitantes & Qualidade & Condição & Idade & Estado & Ocupação \\
\hline José Estevão Cliff & Branco & - & 26 & Solteiro & $\begin{array}{r}\text { Natural dos Estados } \\
\text { Unidos, Médico } \\
\text { e empregado em } \\
\text { mineração }\end{array}$ \\
\hline John Ortuen & Branco & - & 30 & Solteiro & $\begin{array}{r}\text { Inglês, empregado em } \\
\text { mineração }\end{array}$ \\
\hline Thomas Lehul & Branco & - & 40 & Solteiro & $\begin{array}{r}\text { Inglês, empregado em } \\
\text { mineração }\end{array}$ \\
\hline Felício Gonçalves & Pardo & Livre & 24 & Solteiro & Em mineração \\
\hline $\begin{array}{l}\text { Francisco } \\
\text { Gonçalves }\end{array}$ & Pardo & Livre & 20 & Solteiro & Em mineração \\
\hline Anna Joaquina & Parda & Livre & 20 & Solteira & Costureira \\
\hline Roque & Angola & Cativo & 36 & Solteiro & Em mineração \\
\hline Custódio & Angola & Cativo & 50 & Solteiro & Em mineração \\
\hline Manoel & Angola & Cativo & 16 & Solteiro & Em mineração \\
\hline Venâncio & Angola & Cativo & 40 & Solteiro & Em mineração \\
\hline Felício & Angola & Cativo & 38 & Solteiro & Em mineração \\
\hline João & Angola & Cativo & 26 & Solteiro & Em mineração \\
\hline Conrado & Crioulo & Cativo & 26 & Solteiro & Em mineração \\
\hline Joaquim & Angola & Cativo & 16 & Solteiro & Em mineração \\
\hline Theodoro & Angola & Cativo & 18 & Solteiro & Em mineração \\
\hline Antônio & Angola & Cativo & 16 & Solteiro & Em mineração \\
\hline Messias & Angola & Cativo & 18 & Solteiro & Em mineração \\
\hline José & Angola & Cativo & 19 & Solteiro & Em mineração \\
\hline Manoel & Angola & Cativo & 20 & Solteiro & Em mineração \\
\hline Antônio & Moçambique & Cativo & 24 & Solteiro & Em mineração \\
\hline Caetano & Angola & Cativo & 18 & Solteiro & Em mineração \\
\hline
\end{tabular}


Continuação

\begin{tabular}{|c|c|c|c|c|c|}
\hline Joaquim & Angola & Cativo & 20 & Solteiro & Em mineração \\
\hline Cipriano & Angola & Cativo & 16 & Solteiro & Em mineração \\
\hline Garcia & Angola & Cativo & 18 & Solteiro & Em mineração \\
\hline Patrício & Angola & Cativo & 16 & Solteiro & Em mineração \\
\hline Messias & Angola & Cativo & 20 & Solteiro & Em mineração \\
\hline José & Angola & Cativo & 22 & Solteiro & Em mineração \\
\hline Antônio & Angola & Cativo & 20 & Solteiro & Em mineração \\
\hline Paraíso & Angola & Cativo & 18 & Solteiro & Em mineração \\
\hline Cassimiro & Angola & Cativo & 16 & Solteiro & Em mineração \\
\hline João & Angola & Cativo & 20 & Solteiro & Em mineração \\
\hline Duarte & Angola & Cativo & 18 & Solteiro & Em mineração \\
\hline Paulo & Angola & Cativo & 24 & Solteiro & Em mineração \\
\hline Marcos & Angola & Cativo & 20 & Solteiro & Em mineração \\
\hline Pedro & Angola & Cativo & 14 & Solteiro & Em mineração \\
\hline Raimundo & Angola & Cativo & 20 & Solteiro & Em mineração \\
\hline Onofre & Angola & Cativo & 16 & Solteiro & Em mineração \\
\hline Joaquim & Angola & Cativo & 18 & Solteiro & Em mineração \\
\hline Jassinto & Angola & Cativo & 16 & Solteiro & Em mineração \\
\hline Antônio & Angola & Cativo & 18 & Solteiro & Em mineração \\
\hline Marcelino & Angola & Cativo & 16 & Solteiro & Em mineração \\
\hline Luciana & Crioula & Cativa & 14 & Solteira & Em mineração \\
\hline Luzia & Crioula & Cativa & 18 & Solteira & Em mineração \\
\hline Rita & Crioula & Cativa & 20 & Solteira & Em mineração \\
\hline Catharian & Angola & Cativa & 30 & Solteira & Em mineração \\
\hline Bibianna & Angola & Cativa & 36 & Solteira & Cozinheira \\
\hline Vitória & Angola & Cativa & 28 & Solteira & Cozinheira \\
\hline Rosa & Angola & Cativa & 16 & Solteira & Costureira \\
\hline Jacinta & Angola & Cativa & 15 & Solteira & Costureira \\
\hline Sebastianna & Angola & Cativa & 18 & Solteira & Em mineração \\
\hline Rosa & Angola & Cativa & 20 & Solteira & Em mineração \\
\hline Esmeria & Angola & Cativa & 16 & Solteira & Em mineração \\
\hline Januária & Angola & Cativa & 18 & Solteira & Em mineração \\
\hline Magdalena & Angola & Cativa & 24 & Solteira & Em mineração \\
\hline Pulcheria & Angola & Cativa & 17 & Solteira & Em mineração \\
\hline Theresa & Angola & Cativa & 20 & Solteira & Em mineração \\
\hline Antônia & Angola & Cativa & 14 & Solteira & Em mineração \\
\hline Eleutéria & Angola & Cativa & 15 & Solteira & Em mineração \\
\hline Clara & Angola & Cativa & 18 & Solteira & Em mineração \\
\hline Matildes & Angola & Cativa & 20 & Solteira & Em mineração \\
\hline Miquelina & Angola & Cativa & 18 & Solteira & Em mineração \\
\hline Sabina & Angola & Cativa & 14 & Solteira & Em mineração \\
\hline Zeferina & Angola & Cativa & 17 & Solteira & Em mineração \\
\hline
\end{tabular}


Continuação

\begin{tabular}{l|l|l|l|l|r}
\hline Perpétua & Angola & Cativa & 18 & Solteira & Em mineração \\
\hline Senhorinha & Angola & Cativa & 16 & Solteira & Em mineração \\
\hline Silvéria & Angola & Cativa & 15 & Solteira & Em mineração \\
\hline Francisca & Angola & Cativa & 20 & Solteira & Em mineração \\
\hline Cândida & Angola & Cativa & 16 & Solteira & Em mineração \\
\hline Custódia & Angola & Cativa & 22 & Solteira & Em mineração \\
\hline Eulália & Angola & Cativa & 18 & Solteira & Em mineração \\
\hline Gabriella & Angola & Cativa & 14 & Solteira & Costureira \\
\hline Generosa & Angola & Cativa & 20 & Solteira & Em mineração \\
\hline Firmina & Angola & Cativa & 14 & Solteira & Em mineração \\
\hline Ponciana & Angola & Cativa & 24 & Solteira & Em mineração \\
\hline Ignez & Angola & Cativa & 16 & Solteira & Em mineração \\
\hline
\end{tabular}

Fonte: Arquivo Público Mineiro. Mapas de População. MP-CX 01-DOC.04. Disponível em: http://www.siaapm. cultura.mg.gov.br/modules/mapas_populacao/brtacervo.php?cid=64. Acesso em 12/07/2014.

Observa-se que a faixa etária dos escravos da lavra era formada, majoritariamente, por homens e mulheres em plena idade produtiva, ou seja, dos 14 aos 30 anos. Todos solteiros. Dentre os 69 cativos, apenas cinco (quatro homens e uma mulher) ultrapassam este marco etário. Não havia nenhum sexagenário. Este padrão indica não apenas a escolha de trabalhadores com expressivo vigor físico, mas também a pouca longevidade daqueles que eram ocupados numa das mais perigosas atividades laborais.

Veremos abaixo que em 1843 a Brazilian Company empregava 450 trabalhadores; ou seja, um incremento de $600 \%$ no contingente em apenas 12 anos. Uma transformação dessa magnitude certamente provocou diferentes impactos socioeconômicos na localidade.

$\mathrm{Na}$ "Relação das pessoas que têm fábrica no Distrito" anexa ao Mappa anteriormente citado, foram arrolados três proprietários de fábricas de ferro: o capitão José Antônio da Silva, brasileiro nato, que empregava 11 cativos e 1 livre no lugar chamado Marragão; o alferes Antônio José de Souza Machado, "brasileiro adoptivo", que empregava 4 cativos e 5 livres no lugar chamado Bexiga e o furriel Felipe Marinho Cruz, brasileiro nato, que empregava 4 cativos e 6 livres no lugar denominado Valentim. É provável que estes três fossem fornecedores de ferramentas e demais instrumentos à lavra de Cata Branca.

O novo recenseamento realizado 36 anos depois, em 18 de outubro de 1867, registrou sensível crescimento populacional de Itabira do Campo. Foram relacionadas 1.371 pessoas livres e 234 escravas, totalizando 1.605 indivíduos (450 a mais que em 1831). Não há o registro da presença de nenhum estrangeiro na localidade. ${ }^{12} \mathrm{Em}$ termos comparativos, diminuiu a relação número de livres $x$ número de escravos. Isso demonstra que Itabira, assim como a sociedade mineira na segunda metade do século XIX, seguia o gradual processo de emancipação da classe servil e sentia os efeitos do fim do tráfico atlântico de cativos a partir de 1850, dentre outros fatores..$^{13}$

12 Arquivo Público Mineiro. Mapas de População (1867). MP-CX 13-DOC.06. Disponível em: http://www.siaapm.cultura.mg.gov.br/modules/mapas_populacao/brtacervo.php?cid=1120. Acesso em 14/07/2014.

13 O Mapa de População de nascimentos, casamentos e óbitos de Itabira do Campo (1838) que se encontra sob a guarda do Arquivo Público Mineiro está muito deteriorado impossibilitando sua leitura. Por isso, não pôde ser considerado neste estudo - MP-CX.07-DOC.31. 
Tabela 2 - Força de trabalho escravo da Brazilian Company (1831-1845)

\begin{tabular}{c|c|c|c}
\hline Anos & Homens & Mulheres & Contingente \\
\hline 1831 & 34 & 35 & 69 \\
\hline $1835^{1}$ & 76 & 34 & 110 \\
\hline 1842 & -- & -- & 300 \\
\hline 1843 & -- & -- & 450 \\
\hline 1845 & -- & -- & 385 \\
\hline
\end{tabular}

\section{As impressões dos viajantes europeus: prenúncios de fatalidades}

Ao longo do século XIX diversos viajantes europeus de diferentes nações percorreram as estradas de Minas Gerais descobrindo e catalogando suas riquezas naturais dos reinos animal, vegetal e mineral e tecendo comentários sobre a diversidade cultural da província. Para além do interesse científico de conhecer nossa biodiversidade deixaram claro em seus diários que toneladas de ouro ainda jaziam no subsolo à espera das novas tecnologias e maquinários capazes de extraílo em benefício dos investidores. Alguns destes "batedores avançados do capital europeu", como os definiu Mary Louise Pratt ${ }^{14}$, visitaram as companhias auríferas inglesas legando textos que, além de estimular a especulação no mercado financeiro europeu, são fontes nas quais podemos obter preciosas informações sobre o mundo do trabalho na mineração nessa fase de maior incremento de capital, inovações tecnológicas e administração racional do empreendimento quando a mineração era "uma obsessão usual, especialmente para o investimento britânico", ainda segundo a mesma autora. ${ }^{15}$

O primeiro viajante europeu a visitar a Brazilian Company foi o francês, conde de Suzannet. Ele chegou na segunda semana de dezembro de 1842. Neste ano, a mina contava com a força de 300 cativos $^{16}$, entre homens e mulheres. Ou seja, em aproximadamente 11 anos, a mina sofreu um aporte de $394,73 \%$ em sua força de trabalho, comparando com os números de 1831 anteriormente apresentados. Esta maior demanda por mão de obra é claro indício que houve aumento na extração e beneficiamento do minério - fato que não indica, a priori, acréscimo no volume final de ouro apurado, tampouco da lucratividade do empreendimento, embora seja o mais provável.

Suzannet deixou registrado em seu diário ricas e detalhadas informações sobre a companhia. Elogiou o conjunto das instalações da superfície e viu o uso de rodas hidráulicas na trituração do minério. Ele não a observou de fora; desceu em suas galerias, criticou a forma como eram desenvolvidos os serviços no subterrâneo que, segundo ele, foram conduzidos com "pouca inteligência". No subsolo, verificou a largura da galeria de extração e a falta de escoramento das paredes e do teto a 104 braças de profundidade: "Quando eu desci na mina, fiquei espantado de ver os vãos de vinte e cinco e trinta pés de largura

\footnotetext{
14 PRATT, Mary Louise. Os olhos do império: relatos de viagem e transculturação. Tradução de Jézio Hernani Bonfim Gutierre; revisão técnica Maria Helena Machado e Carlos Valero. Bauru: EDUSC, 1999, p. 252.

15 PRATT. Os olhos do império, p. 254.

16 Este número chegou a 385 em 1845, ano de sua venda à Saint John d’El Rey.
} 


\section{suspensos sobre a cabeça dos trabalhadores, sem que nada fosse feito para prevenir um desmoronamento". ${ }^{17}$}

Suzannet visitou os trabalhos interiores ao lado do engenheiro-chefe, um mineiro da Cornualha. Ao adverti-lo sobre o perigo que havia de explorar o veio sob uma largura de trinta pés (aproximadamente 9 metros na convenção métrica atual) ouviu a seguinte resposta dada com uma segurança ingênua: "Não acredito que na França ou na Alemanha haja homens que entendam tão bem quanto nós de exploração de minas". ${ }^{18}$ Face esta resposta, fruto também das rivalidades entre ingleses, franceses e alemães existentes naquela centúria, concluiu que:

O fato é que as companhias inglesas, em vez de confiarem os seus interesses a homens especializados, a geólogos instruídos, enviaram ao Brasil capitães de minas bastante inteligentes sem dúvida para continuar trabalhos já iniciados, mas incapazes de dirigir com sucesso a difícil exploração de uma mina de ouro. Os homens mesmo aqueles que têm experiência do trabalho de todas as outras minas fracassam nesta exploração, cheia de dificuldades e de acasos; a formação do veio do ouro é quase sempre desigual, e se apresenta sob os aspectos os mais variados. Os ingleses, arriscando imensos capitais, não quiseram pedir à Alemanha os únicos trabalhadores que poderiam tornar seus trabalhos produtivos. Em nenhum outro lugar, talvez, a má escolha dos chefes mineiros enviados da Inglaterra produziu resultados tão desastrosos como em Cata Branca. ${ }^{19}$

Outra falha técnico-administrativa apontada pelo autor foi a escolha de oficiais da Marinha para diretores da companhia que confiaram a condução dos trabalhos a "agentes privados dos conhecimentos necessários". Se não fosse por isso, a riqueza do filão de Cata Branca poderia cobrir facilmente as despesas de exploração.

Ao partir de Itabira, Suzannet se dirigiu a outra companhia inglesa, a mina de Morro Velho. Ali, observou que, graças à inteligência de Mr. Herring, "os desmoronamentos lhe são desconhecidos, e os trabalhos, desenvolvidos com uma grande atividade, são sempre conduzidos pensando no futuro". ${ }^{20}$

Praticamente um ano depois de Suzannet, seu patrício, Francis de La Porte Castelnau chegou à Brazilian Company no dia 19 de dezembro de 1843, por ele

17 SUZANNET, Comte de. Souvenirs de voyages. Les provinces du Caucase, l'empire du Brésil. Paris: G. A. Dentu, Imprimeur-Libraire, 1846. Brasiliana Digital (USP), p. 301. No original: “lors-que je descendis dans la mine, je fus etonné de voir des voûtes de vingt-cinq et trente pieds de largeur suspendus au-dessus de la tête des travailleurs, sans que rien fût fait pour prevenir un éboulement". Tradução e negritos nossos.

18 SUZANNET, Comte de. Souvenirs de voyages., p. 302. No original: Je ne pense pas que en France ou en Allemagne il y ait des hommes qui s'entendent aussi bien que nous à l'exploitation des mines'”. Tradução nossa.

19 SUZANNET, Comte de. Souvenirs de voyages., p. 302. No original: "Le fait est que les compagnies anglaises, au lieu de confier leur intérets à des hommes spéciaux, à des géologues instruits, ont envoyé au Brésil des capitaines-mineurs assez intelligents sans doute pour continuer des travaux déjà commencés, mas incapables de diriger avec succès l'exploitation si difficile d'une mine d'or. Les hommes même qui ont expérience du travail de toutes les autres mines échouent dans cette exploitation, pleine de difficultés et de hasards; la formation de la veine d'or est presque toujours inégale, et se presente sous les aspectes les plus différents. Les Anglais, tout en exposant d'immenses capitaux, n'ont pas voulu demander à l'Allemagne les seuls travailleurs qui pussent rendre leurs travaux productifs. Nulle part peut-être le mauvais choix des chefs mineurs envoyés d'Angleterre n'a produit d'aussi facheux résultats qu'à Catta-Branca". Tradução e negrito nossos.

20 SUZANNET, Comte de. Souvenirs de voyages, p. 305. No original: "les éboulements y sont inconnus, et les travaux, poussés avec une grande activité, sont toujours conduits dans une pensée d'avenir”. Tradução nossa. 
considerada "uma das minas de ouro mais ricas do Brasil". ${ }^{21}$ Foi recebido pelo Sr. Champion, diretor da empresa. Alegando problemas de saúde, Castelnau não visitou todos os trabalhos da mina. Preferiu servir-se das anotações extraídas do diário do médico e botânico Hugh Weddel e das observações científicas do engenheiro de minas, o visconde Eugène d'Osery que o acompanhavam na viagem e que descrevem detalhadamente as etapas, o maquinário e a rotina de trabalho na superfície e no subterrâneo que passamos a citar livremente. ${ }^{22}$

É importante destacar que nesses dois documentos que Castelnau se serviu são nítidas as precárias condições de trabalho, o ambiente malsão e a insegurança a que os trabalhadores estavam submetidos no subsolo.

Quando o Sr. Weddel e o capitão William, um velho mineiro da Cornualha, entraram na mina tiveram que se equipar com o vestuário dos mineiros. A galeria principal de entrada na mina era bastante úmida chegando a água "até a altura de um pé". O excesso de água era retirado por meio de bombas de esgotamento. Ao final da galeria de entrada era necessário descer num poço muito escuro através de uma escada de ferro que os conduziu a uma primeira plataforma para, em seguida, chegarem à segunda plataforma descendo outra escada e assim por diante chegando a 300 metros abaixo da superfície. "O que nos foi dado ver então pareceu-nos bem infernal”, registra o relatório de Weddel:

Tochas estavam presas aqui e ali às paredes da mina, cuja extensão, no ponto em que estávamos a quarenta pés; essa luz clareava o corpo retinto dos negros, que estavam vestidos só na metade do corpo e apareciam em grupos de três, em torno dos buracos que abriam no quartzo. O suor escorria na pele luzente destes mineiros, como que para harmonizá-los com as bicas que corriam das paredes da escavação; feria o ouvido as pancadas repetidas dos pesados martelos sobre os escopros, ruído este que se casava ao barulho feito pela água e ao rangido de corrente de ferro, quando ela fazia descer até junto de nós o balde em que se transportava o minério. Bastante singular esse espetáculo.23

A descrição revela que a Mina de Cata Branca possuía grande verticalidade, pois para se chegar aos salões de extração era necessário descer em "poços" através dos quais se erguiam o minério em baldes até à superfície, diferentemente das minas onde se adotavam os planos inclinados de acesso. Ao descrever o caminho de volta, fica ainda mais nítido como o ambiente de trabalho no subterrâneo era cercado de perigos. A certa altura, diz, "ao ser necessário passar por uma estreita prancha lançada sobre a boca de um grande poço, mais três dos nossos companheiros nos abandonaram. Veio depois longa e estreita galeria, cuja altura teria quando muito um metro e cheia de água até meia altura". Cruzaram outras galerias ainda mais estreitas e úmidas "junto a tubos de bomba e muitas vezes com braços de alavancas em movimento". Não é de se estranhar que a empresa necessitasse de um hospital..., assim como também o tinham a The Ouro Preto Gold Mines of Brazil Limited em Mariana/MG e a Saint John d'el Rey Mining Company instalada em Nova Lima/MG.

21 CASTELNAU. Expedições às regiões centrais da América do Sul, p. 160.

22 CASTELNAU. Expedições às regiões centrais da América do Sul, p. 161ss.

23 CASTELNAU. Expedições às regiões centrais da América do Sul, p. 162s. Vimos anteriormente (p. 11) que havia um vestuário típico do mineiro composto "de grossas camisas de lã e chapéus de feltro". Este trecho do relatório demonstra que não se observava estritamente seu uso no dia a dia, provavelmente devido ao calor subterrâneo. Até mesmo o chapéu que visava proteger minimamente a cabeça era desprezado. As fotos de Marc Ferrer tiradas na mina de Morro Velho no século XIX comprovam que os trabalhadores usualmente trajavam apenas uma calça deixando o tronco e a cabeça descobertos. 


\section{A rotina de trabalho}

O "padrão inglês" de administrar e desenvolver os serviços de extração e beneficiamento do minério aurífero era basicamente o mesmo adotado em todas as companhias britânicas instaladas em Minas Gerais no século XIX. As técnicas, ferramentas e instrumentos empregados variaram em conformidade com as inovações e invenções advindas com o tempo. Não obstante, recursos antigos (como a bateia) coexistiram com os mais modernos (vagonetes e perfuratrizes, por exemplo); uns foram suplantados, outros permaneceram.

A Brazilian Compay, a quarta companhia aurífera inglesa a se instalar em Minas Gerais, funcionava 24 horas por dia dividido em três turnos de trabalho de oito horas. ${ }^{24} \mathrm{O}$ serviço extrato-produtivo era dividido em dois setores básicos: subsolo e superfície. No primeiro, na frente de extração para efetuar o desmonte das rochas formavam-se grupos de trabalho compostos pelos escravos mais fortes e hábeis "notáveis pela robusta aparência e aspecto sadio" 25 chefiados por mineiros ingleses. Ao tempo de Suzannet, ali trabalhavam 40 negros. Suas principais ferramentas de trabalho eram a alavanca, o marrão, o picão e o almocafre usados para perfurarem as rochas que em seguida eram transportadas para fora em carumbés colocados sobre a cabeça dos escravos.

O vestuário de trabalho usado pelos escravos ocupados nos serviços subterrâneos era composto de grossas camisas de lã e chapéus de feltro breados de resina na qual se colava a candeia para deixar as mãos livres e ter maior facilidade de movimentos. A iluminação interna das galerias era feita com tochas.

Chegando à superfície, o minério extraído dos poços era levado pelos negros e entregues aos escravos do setor de trituração que o reduziam a pequenos fragmentos. Estes eram então colocados nos pilões de ferro (movidos por rodas motrizes hidráulicas de quarenta pés de diâmetro). ${ }^{26}$ Em seguida, a massa produzida era arrastada pela água e deixava para trás o metal no fundo dos pilões. 0 ouro sobrenadante era retido em pedaços de pano colocados no plano inclinado instalado imediatamente abaixo dos pilões. Passava-se então à lavagem manual em bateias que recolhiam este ouro em pó. O processo final de purificação do metal era feito com mercúrio submetido ao calor que volatilizava e deixava "o ouro em estado de pureza". Estas etapas da separação mecânica eram, de maneira geral, desempenhadas por mulheres; além de serem estas as cozinheiras e costureiras da mina.

24 É quase desnecessário lembrar que essa jornada de oito horas não era regra, pois uma das características do trabalho servil é a extensão da jornada de trabalho ao máximo possível.

25 CASTELNAU. Expedições às regiões centrais da América do Sul, p. 160.

26 Ao tempo de Castelnau eram três máquinas hidráulicas; quando da visita de Suzannet esse número subiu para cinco. De acordo com Richard Burton, inicialmente, a Brazilian Company adotou "antiquada prática de 'britar', ou melhor 'esmagar', por meio de mós feitas de material quartzoso duro e resistente; logo depois, entrou em operação a melhor maquinaria do império" - BURTON. Viagem do Rio de Janeiro a Morro Velho, p. 164 . 


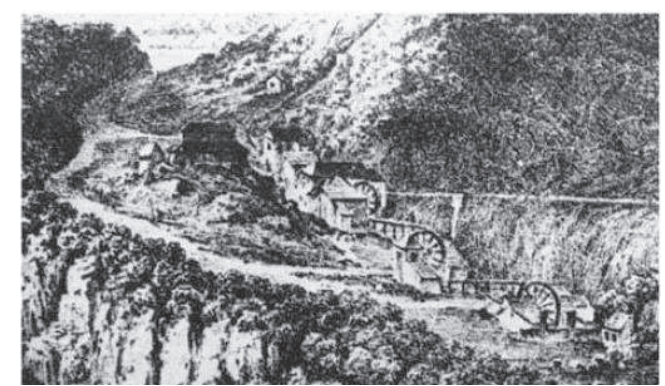

Legenda: Montes Auriferi Ad Cata Branca. August Brandmeyer. Disponível em: www.org.ufmg.br/nehcit/ itabirito/mina.php. Aceso em 15/09/2015.

As obras dos dois viajantes mostram que havia uma política de premiação e castigos aplicados aos escravos. Àqueles que demonstravam bom comportamento prometia-se a liberdade e recebiam 50 cêntimos aos domingos quando sua conduta era boa durante a semana. A companhia permitia que eles cultivassem hortas "onde eles cultivam quase todos os legumes da Europa e aqueles do país". ${ }^{27}$ Após a jornada de trabalho podiam dispor do tempo livre a seu gosto e recebiam pagamento pelos serviços que realizavam. ${ }^{28}$

Castelneau ficou impressionado com o aspecto nitidamente inglês e a extrema limpeza dos jardins floridos em frente às habitações da povoação. Isto porque, segundo Gilberto Freyre, os ingleses instalados nos trópicos traziam consigo seus hábitos sociais como garantia de sua singularidade e superioridade. ${ }^{29}$ Observou que os "dormitórios" usados pelos negros eram "altos, bem arejados e guarnecidos, em ambos os lados, de leitos dispostos em dois andares e perfeitamente limpos". ${ }^{30}$

Outro viajante que conheceu a mina de Cata Branca quando esta então já pertencia à Saint John d'El Rey Mining Company foi o inglês Richard Burton em 1867. Embora a visita diste 22 anos da aquisição, suas observações fornecem importantes contribuições para a história desta empresa. A primeira anotação relevante para a história das relações hierárquicas no local de trabalho diz respeito ao perfil que ele traça de um dos superintendentes da Brazilian Company que iniciou os trabalhos em 1833, o "Comandante Cotesworth". Diz ele se tratar de "um disciplinador rigoroso, ativo e enérgico (...) rabugento no que dizia respeito aos seus direitos e 'zeloso no cumprimento de seu dever"'. ${ }^{31}$ Este tipo de administrador, "então apreciados na Inglaterra", não media esforços para ministrar o doce e o amargo a seus subalternos, sobretudo aos escravos.

\section{Acidentes e falência}

“Nas minas, como nas estradas de ferro, a causa do fracasso, repito,
está, não nos brasileiros, mas em nós” (BURTON, 1976, p. 186).

É preciso entender as razões da curta vida útil da Brazilian Company, visto

27 SUZANNET, Comte de. Souvenirs de voyages, p. 301. No original: “(...) où ils cultivent presque tous les legumes d'Europe e ceux du pays". Tradução nossa.

28 O autor não especifica quais eram esses serviços extras.

29 FREYRE, Gilberto. Ingleses no Brasil: aspectos da influência britânica sobre a vida, a paisagem e a cultura do Brasil. 2. ed. Rio de Janeiro: Livraria José Olympio, 1977.

30 CASTELNAU. Expedições às regiões centrais da América do Sul, p. 160. É preciso esclarecer que as companhias "maquiavam" as instalações quando sabiam previamente que receberiam visitas para causar boa impressão e, assim, evitar críticas.

31 BURTON. Viagem do Rio de Janeiro a Morro Velho, p. 164. 
que este fator está diretamente relacionado com as condições geológicas do terreno, com as técnicas extrativas vigentes, com as decisões administrativas, com falta de medidas de segurança adotadas e com as condições de trabalho às quais estavam submetidos os mineiros escravos e livres, nacionais e estrangeiros.

Richard Burton atribui duas causas a esse fracasso: primeira, a "total ausência de economia"; e, segunda, "os trabalhos foram mal feitos", pois "a jacutinga era, então, uma formação desconhecida, mas os mineiros ingleses, especialmente os da Cornualha, já sabiam tudo e, por conseguinte, não toleravam que lhes ensinassem coisa alguma". Acrescenta que esses homens "práticos" que "haviam adquirido, empiricamente, alguns conhecimentos de Mineralogia, nenhum de Geologia” foram contratados porque além de receberem uma remuneração inferior à de um "teórico" na Inglaterra "ainda se agarram à velha superstição do conhecimento empírico". ${ }^{2}$

A esta observação podemos acrescentar a opinião do balizado engenheiro Paul Ferrand que também fornece as razões de sua trágica e efêmera atividade da seguinte maneira:

\begin{abstract}
A lavra era prejudicada por entrada abundante de água. Como o aprofundamento era sempre feito por meio de grandes escavações, sem preenchimento e com madeirame restrito aos pontos perigosos, chegou num momento em que uma das paredes, minada pelas águas, produziu uma pressão enorme sobre o escoramento e desabou em 1844, enterrando cerca de trinta mineradores sob seus escombros. Essa queda foi devida a duas causas: a economia nos trabalhos e um mau método de explotação. 33
\end{abstract}

O resultado prático dessa inépcia e incúria administrativa para os trabaIhadores foram os inúmeros desabamentos ocorridos na mina como aquele que ceifou a vida de 11 escravos informado (sem precisar a data) a Suzannet no ano de sua visita, os "desabamentos parciais que fizeram um pequeno número de vítimas, não se conta mais" 34 e aquele de maiores proporções que levou ao óbito cerca de 30 trabalhadores em $1844^{35}$. Vale lembrar que, antes de 1830 , anterior à compra pelos ingleses ocorreu um desmoronamento que "acarretou a morte de várias pessoas, fazendo com que sua exploração fosse suspensa". ${ }^{36}$ Isso demonstra que o descuido com a segurança no local de trabalho era crônico.

Antônio Olynto dos Santos Pires descreveu com maior riqueza de detalhes esse grande acidente de 1844. O autor relata que "o desabamento de uma grande pedra no poço vertical fez abater parte de suas paredes e fechou galerias, onde trabalhavam mais de cem operários. Depois de inúmeros esforços para salvar os vivos, sepultados pela catástrofe, foi preciso inundar a mina para findar esse suplício". 37 E acrescenta:

\footnotetext{
BURTON. Viagem do Rio de Janeiro a Morro Velho, p. 164.

3 FERRAND. O ouro em Minas Gerais, p. 185.

34 SUZANNET, Comte de. Souvenirs de voyages, p. 303. No original: "quant aux éboulements partiels que n'ont fait qu'un petit nombre de victimes, on ne les compte plus". Tradução nossa.

35 Segundo Richard Burton, foram apenas treze trabalhadores, entre os quais, um inglês. Cf. BURTON. Viagem do Rio de Janeiro a Morro Velho, p. 164.

36 CASTELNAU. Expedições às regiões centrais da América do Sul, p. 164.

37 RIMG. 1893. Anno I, n. 3, p. 68. Burton (1976, p. 164) sustenta que apenas "treze trabalhadores, entre os quais um inglês, foram mortos; alguns aumentam o número, que outros afirmam ser exagerado”.
} 
Conta-se que durante alguns dias ouviam-se nas entranhas duríssimas da rocha os gemidos de muitas dessas vítimas soterradas pelos desmoronamentos. Frustrados todos os serviços de socorro, quando não houve mais esperança de salvar os vivos sepultados pela catástrofe por impossibilidade absoluta de atravessar a massa rochosa que os separava de fora, a solução mais humana que se encontrou para minorar os seus sofrimentos foi inundar a mina com as águas das máquinas exteriores e fazer perecer por asfixia os que teriam de morrer por inanição angustiosíssima.

E lá estão enterradas naquele gigantesco túmulo de rocha as centenas dos mineiros infelizes que encontraram a morte perfurando as entranhas da terra para lhe aproveitar os tesouros. ${ }^{38}$

Do ponto de vista técnico constata-se, portanto, que esses acidentes foram causados pela insuficiência ou mesmo pela falta de escoramento do teto e das paredes das galerias que tinham grandes diâmetros e pelo excesso de umidade no subsolo, indicando falhas no sistema de drenagem, como vimos nos relatos de Suzannet e Castelnau. 39 "Economia nos trabalhos" nada mais é que eufemismo para disfarçar a ganância dos administradores que negligenciavam as mais elementares regras de segurança no trabalho subterrâneo: fazer o eficiente esgotamento das águas e o escoramento do teto e das paredes da mina com grossas e adequadas madeiras ou com "pedra seca" (aquela que não contém o ouro) em intervalos que garantam a estabilidade das galerias que não podem atingir diâmetros muito elevados. Essa negligência torna-se ainda mais grave quando se sabe que a formação geológica de Cata Branca era composta, predominantemente, de jacutinga: material muito friável que exige escoramentos próximos e robustos. As minas de jacutinga são mais suscetíveis a desabamentos.

No texto de Suzannet vimos que era necessário "tratar quinze toneladas de minério para obter uma libra de ouro" pois a mina já não era tão produtiva como antigamente, sendo que "a quantidade de pedra extraída por dia é aproximadamente de dezoito a vinte toneladas". Nas entrelinhas deste fragmento percebe-se que os trabalhos de desmonte eram feitos de forma acelerada para compensar a baixa relação rocha extraída $x$ ouro apurado. E mais, se a mina não tivesse uma boa reserva de mata próxima de onde pudesse retirar as madeiras necessárias e adequadas ela precisava adquiri-las, onerando ainda mais suas contas e reduzindo a taxa de lucratividade. Talvez por isso Ferrand tenha falado em "economia nos trabalhos". ${ }^{40}$

Assim, em dezembro de 1842, as ações da companhia não valiam mais de 150 francos e nenhum dividendo foi pago aos acionistas desde sua fundação. E, segundo Suzannet, nenhuma mudança favorável se operara nas explorações da mina. ${ }^{41}$

Em resumo, a ganância dos administradores, a contratação de capitães de mina incapazes e mais baratos, o desconhecimento da geologia, a excessiva confiança no conhecimento prático dos mineiros ingleses, o descuido com a segurança (escoramento e drenagem) estão diretamente relacionados aos

38 Publicado originalmente no Almanaque de Ouro Preto em 1890. Citado por VEIGA, José Pedro Xavier da. Efemérides mineiras: 1664-1897. Introdução Edilane Maria de Almeida Carneiro, Maria Eloísa Melgaço Neves; pesquisa histórica Bruno Fagundes; leitura paleográfica e atualização ortográfica Cláudia Alves Melo. Belo Horizonte: Centro de Estudos Históricos Culturais; Fundação João Pinheiro, 1998, p. 965.

39 É provável que as observações de Richard Burton e de Paul Ferrand sejam fruto da leitura das obras destes viajantes, bem como dos relatórios da companhia.

40 Aqui, parece haver contradição entre Burton que fala em "total ausência de economia" e de Ferrand que afirma ter havido "economia nos trabalhos". Sabemos que Burton criticara em outras partes de seu texto o caráter perdulário dos administradores das companhias inglesas que viviam faustosamente. Provavelmente é a isto que ele se refere.

41 SUZANNET, Comte de. Souvenirs de voyages, p. 304. 
desmoronamentos e mortes dos trabalhadores e, por conseguinte, à falência prematura do empreendimento. Estes são os fatos irretorquíveis que as fontes nos revelaram. ${ }^{42}$

Esses mesmos problemas podem ser encontrados na trajetória de outras companhias e apontados como as principais causas dos acidentes que nelas ocorreram: a National Brazilian na mina de Cocais teve sua operação interrompida por causa de um desmoronamento ocorrido em 1847. Da mesma forma, as atividades da Saint John d'el Rei Mining Company ficaram paralisadas durante anos após o grande acidente de 10 de novembro de 1886. Além desses sinistros mais graves ocorriam outros de menores proporções em todas essas minas que, somados, certamente atingem índices alarmantes, como os verificados na mina de Morro Velho e na de Passagem de Mariana durante seu funcionamento que de tão corriqueiros nem se contavam mais.

A força de trabalho escravo na mina esteve em permanente crescimento desde a fundação da companhia, sofrendo ligeiro declínio em 1845. Sabemos que no ano anterior, 1844, ocorreu um grande desmoronamento "resultando em um número de mortes que nunca foi apurado". ${ }^{43}$ Em 1845 foram alugados pela Brazilian Company à Saint John d'El Rey Mining Company 385 escravos por um período de 14 anos numa transação que teve repercussões internacionais escandalosas ao ser denunciada pelo deputado Joaquim Nabuco em 1879, quarenta anos depois.

As falências da Brazilian Company e da Imperial Brazilian Mining Association provocaram tanto a queda da produção aurífera de Minas Gerais ("de cerca de $1.700 \mathrm{~kg}$ para quase $1.300 \mathrm{~kg}$, no ano seguinte ao desabamento") quanto a queda das transações mercantis escrituradas na cidade de Ouro Preto. A este fator também está associado o refluxo dos investimentos britânicos na mineração que somente foram retomados na década de 1860.44

Observador arguto, Burton sempre conversava com os moradores dos lugares por onde passava. Em Itabira do Campo, sentado dentro de uma venda na Praça de Santa Teresa bebendo café, ouviu muitos casos dos velhos dias da localidade "em que os habitantes do lugar arranjavam empregos para os filhos, casavam as filhas com ingleses e gozavam da excitação dos lucros e perdas. Itabira progrediu com a Mina de Cata Branca e decaiu quando a mina afundou". 45

\section{Considerações finais}

Não se pode negar que a Brazilian Company e as outras companhias de mineração inglesas dinamizavam o comércio local de secos e molhados, de escravos e de terras, estimularam o desenvolvimento de atividades satélites que forneciam seus produtos e serviços à companhia e aos trabalhadores além de gerar postos de trabalho para a população nas localidades onde se instalaram. Por outro lado, não se pode esquecer que a atividade mineradora modificou sua tessitura social, degradou o ambiente, explorou o trabalho de crianças, elevou a taxa de criminalidade e de prostituição. Além disso, descendo um pouco mais fundo nas "galerias

42 As fontes às quais recorremos não citam a ocorrência de qualquer forma de luta dos trabalhadores da companhia contra estas condições.

43 LIBBY. Transformação e trabalho em uma economia escravista, p. 276.

44 ANDRADE. "Fortunas subterrâneas", p. 9.

45 BURTON. Viagem do Rio de Janeiro a Morro Velho, p. 165. 
da vida", cumpre lembrar que o impacto foi duro também para os parentes dos mineiros soterrados nos diversos acidentes. Famílias foram dilaceradas com a morte de pais e filhos e nada disso foi contabilizado numa fase da história do trabalho onde não havia qualquer forma de indenização aos familiares ou punição aos responsáveis por este tipo de perda.

A história não pode continuar negligenciando a dor e o sofrimento de homens e mulheres provocados por estas fatalidades em nome dos "benefícios legados" pelas companhias inglesas (geração de postos de trabalho, aumento da arrecadação fiscal, incremento do comércio). O ofício do historiador, como sabiamente lembrou Eric Hobsbawm, é justamente levantar a rocha que esmaga a história da classe trabalhadora que a classe dominante tanto quer ver soterrada; lembrar aquilo que ela prefere deixar no esquecimento. Sob este ponto de vista entende-se melhor a dificuldade de localizar dados mais precisos e detalhados sobre esses sinistros que jazem sob os escombros do passado, assim como os mineiros mortos nessa e em tantas outras companhias inglesas que extraíram ouro em Minas Gerais nos séculos XIX e XX.

Recebido em 15/11/2015

Aprovado em 16/01/2016 